\title{
Computer System for Perception of Lung Cancer
}

\author{
Rakhi Nautiyal, Anil Dahiya, Priyanka Dahiya
}

\begin{abstract}
Detection of cancer in its previous stages to increases survival rate of patient. CAD system is efficient because it take minimum time to detect weather the patient has cancer or not. It is very difficult for detection of lung cancer its earlier stage as it takes many tests. There are many of the CAD system which is designed for earlier detection of tumors. Many CAD systems have been designed in past for early detection of lung tumor. For segmentation purpose Thresholding is used and detection of area in which suspected tumor part growing algorithms is used. There are various factor is calculated using GLCM. Multilayer feed forward BPNN approaches for classify the feature set. Performance is calculated in form of mean square error (MSE) using BPNN. The CAD (computer aided diagnosis) model gives $\mathbf{9 0 \%}$ true count. For implementation purpose MATLAB is used.
\end{abstract}

Keywords-CAD, Back Propagation Neural Network, Region of Interest, Computed tomography.

\section{INTRODUCTION}

C ancer begins in cells when body start grows out of control. Because of damage to DNA cell become cancerous. In normal case cell become damage or dies. In damaged dna cancerous cell does not improved and does not die. Rather then it continuously structure new cells in the body. When the tumor size increase then weakness the capability of lung to provide the good stream combination with oxygen[10]. Treatment for a tumor is possible by tests and it can be stopped propagates in further part of our body. Identification of cancer its previous stages known as tumor, it termed as cancer when it reaches to the uncontrollable stage. This paper presents a system for find the suspected reign for lung cancer using CT images.

\section{CAD SYSTEM}

Many computer system have been designed in previously for classify the lung cancer. Computer-aided systems identify and mark suspicious regions on images to bring them to the attention of radiologists. There are various techniques of machine by which the system learn. the system design analyze the tumor area and predict the maligancy.

Revised Manuscript Received on October 31, 2019.

* Correspondence Author

Rakhi Nautiyal *, Department of ITt, DIT University, India. Email: priya.dahiya@dituniversity.edu.in

Anil Dahiya, Department of IT, DIT University, India. Email: rakhi.nautiyal@dituniversity.edu.in

Priyanka Dahiya, Department of IT, DIT University, India. Email: hod.it@dituniversity.edu.in
In this CAD system mainly consists of four stages, preprocessing, extraction of region of interest, feature extraction of feature and classification.due to the less noise effect, CT image is used more than $20 \%$ including reference section.In the case of exclusion of references, it should be less than $5 \%$.

\section{LITERATURE REVIEW}

The Detection of lung cancer various contributions have been made in past few year. Shiying Hu et al[8] proposed a work using dip and Gabor filter within Gaussian rule for detection of lung cancer. Three types of Enhancement techniques is used that is Auto Enhancement, Gabor filter, fast Fourier transform. Gabor filter give best results. TAN Shanjun et al[2] proposed a CAD system by using an ANN. The result of all datasets of the test the accuracy was $95.5 \%$ and $73.3 \%$, respectively for accuracy of ANN and Detrimental analysis. ANITA CHAUDHARY et al[1] gives two classification algorithm that is FFNN and BPN. In this methodology is form of 0 and 1 , if the patient has cancer then input is taken 1 otherwise 0.transfer function is sigmoid.

Jaspinder Kaur et al[3] proposed a CAD ANN system combine with tumor markers with some clinic methods. A total of 140 samples are obtained. Neural network with BP algorithms were performed. The model was developed by training and testing of the ANN was implemented by means of sigmoidal transfer function. The 5 tumor values were then used as ANN input data. Throughput of system analysis was $95.5 \%$ and $73.3 \%$, respectively. Analysis of multiple tumor markers based on ANN is a better choice than the traditional statically method for differentiating hepatic carcinoma from benign and normal

Mellisa Pratiwi et al[4] had done a survey on cancer prediction using neural network technologies for classification of cancer. Such as single layer NN, multi-layer $\mathrm{NN}$ and various kind of machine learning and statically approach as SVM, k nearest neighbor, decision tree[9]. In present time many researcher works on neural network techniques because it provide good classification rate. MLP give $97 \%$, PNN give $96 \%$, and SFNN give 93\%, accuracy[6].

\section{PROPOSED WORK}

The system containing various stages. For the processing of system here I used CT images.

1. Image Preprocessing: CT image applied to system. In this to enhance the image quality we use various digital images processing approach. 


\section{Computer System for Perception of Lung Cancer}

a) Noise Removal: image is originaly contain the noise part to remove these median filter techniques is used.

b) Image Enhancement: for improvement the quality of images.

c) Morphological Operation: It perform opening and closing.

d) Image Segmentation: to divide the images into different object used segmentation.

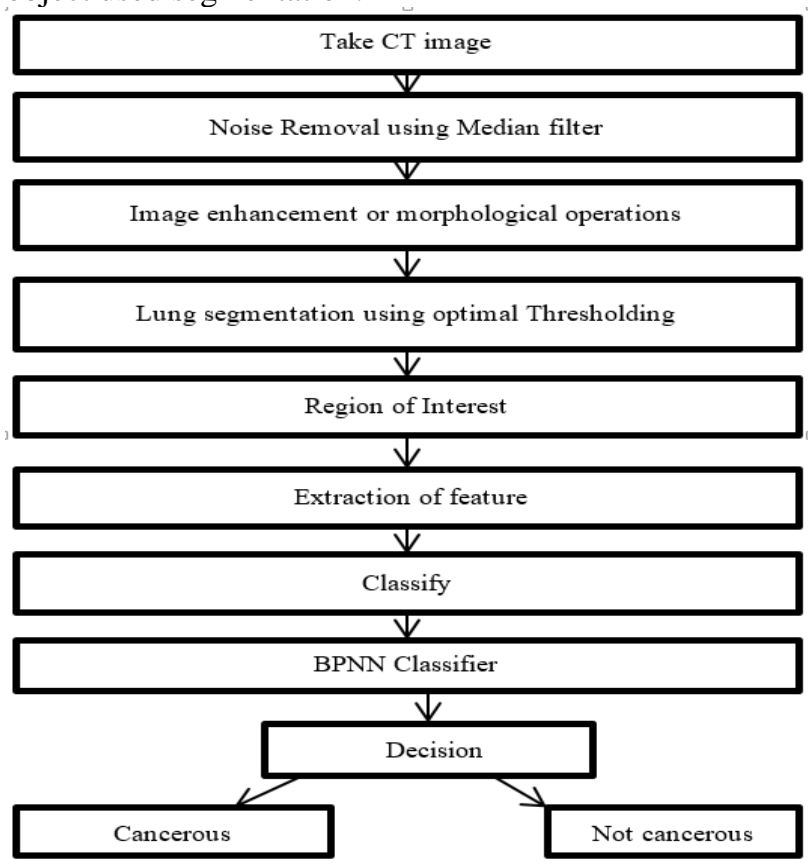

Fig.1. Proposed system
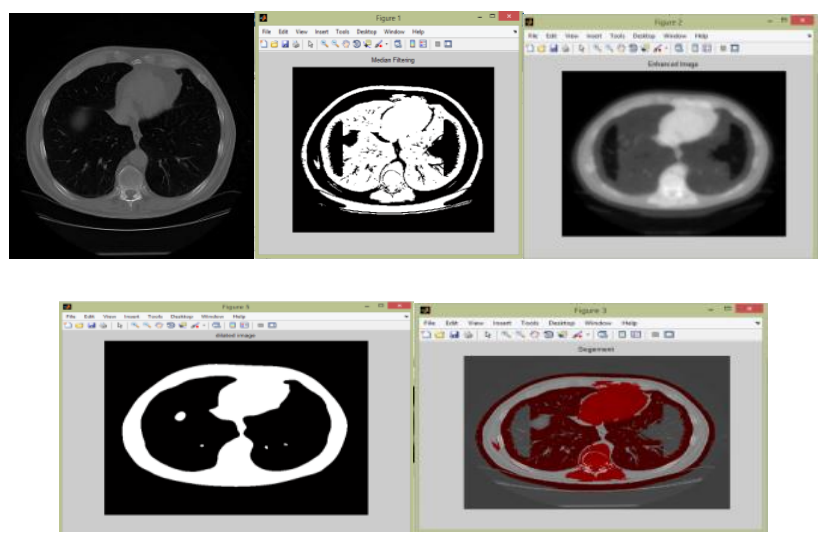

Fig.2. Preprocessing steps For Image 1
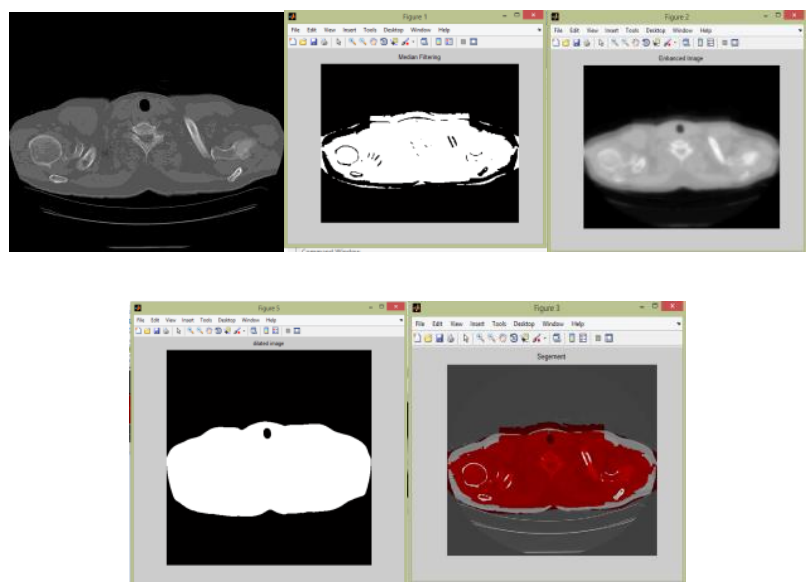

Fig.3. Preprocessing steps For Image 2
2. Extraction of ROIS: after the segmentation of images ROIs is detected. Region growing algorithm is used for this. In this approach seed point is consider[5]. It check further for neighbor pixel for next and continuously do. A pixel value is added into the area when difference between the next point and region is less than the threshold, else algorithm completed.

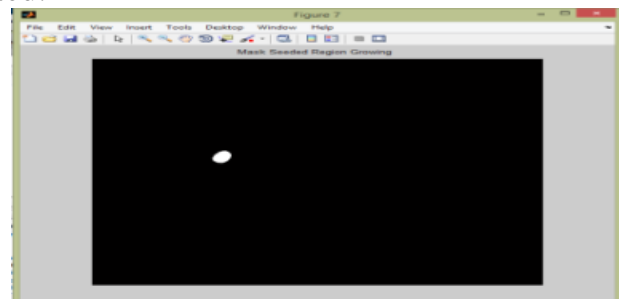

Fig.4. Region of Intrest of image 1

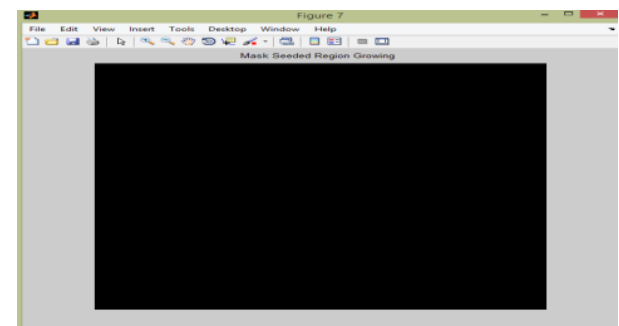

Fig.5. Region of Intrest of image 2 (No Region Detected)

3: Feature extraction: Features are selected from the ROIs of images. GLCM Matrix method is used for feature calculation. Some features are:

1) Energy: =

2) Entropy = -

3) Contrast $=\Sigma_{i} \Sigma_{j} g_{i j} \log _{2} g_{i j}$

4) Variance:

$=$ where is mean of

5) Homogeneity:

Homogeneity $($ hom $)=$

6) Correlation:

Correlation $=$

Where the means and standard deviations of $g_{x}$ and $g_{y}$

7) Sum Average

Sum Average $=$

8) Sum Entropy:

9) Sum Variance:

$$
=
$$

10) Difference Variance: $=$ variance of $g_{x-y}$

11) Difference Entropy:

$=$ 
12) Maximum Correlation Coefficient:

$$
\begin{gathered}
(\mathrm{MCC})=(\text { second largest eigen value of } \mathrm{Q})^{0.5} \\
\text { Where } \mathrm{Q}(\mathrm{I}, \mathrm{j})=
\end{gathered}
$$

13) Information Measures of Correlation: Information measure of correlation $1(\mathrm{IMC} 1)=$ Information measure of correlation $2(\mathrm{IMC} 2)=$ entropies of $\mathrm{g}_{\mathrm{x}}$ and $\mathrm{g}_{\mathrm{y}}$ are $\mathrm{HX}$ and $\mathrm{HY}$.

$$
\begin{gathered}
H X Y 1==-\sum_{i} \sum_{j} g_{i j} \log _{2}\left\{g_{x}(i) g_{y}(j)\right\} \\
H X Y 2==-\sum_{i} \sum_{j} g_{x}(i) g_{y}(j) \log _{2}\left\{g_{x}(i) g_{y}(j)\right\}
\end{gathered}
$$

4. Classification: All the parameter of images are calculated from the ROI of the images. Then classify by the back propagation neural network and mean square error is calculated. The classification is based on performance matrices.

\begin{tabular}{|l|l|}
\hline Accuracy & TP+TN/TP+FP+TN+FP \\
\hline Sensitivity & TP/TP+FN \\
\hline Specificity & TN/TN+FP \\
\hline Quality & TP/FN+FP+TP \\
\hline correctness & TP/TP+FP \\
\hline
\end{tabular}

Table.1.Performance Matrices Formulas

\section{EXPERIMENTAL RESULTS}

The results shows that the classification Accuracy, Sensitivity, Specificity, Quality, Correctness is achieved upto $83 \%, 76 \%, 90 \%, 72 \%, 92 \%$.mimimize mean square error.

\begin{tabular}{|c|c|}
\hline $\mathrm{TP}=215$ & $\mathrm{FP}=21$ \\
\hline $\mathrm{FN}=60$ & $\mathrm{TN}=204$ \\
& \\
\hline
\end{tabular}

Table. 2. Binary classification confusion matrix for BPNN training

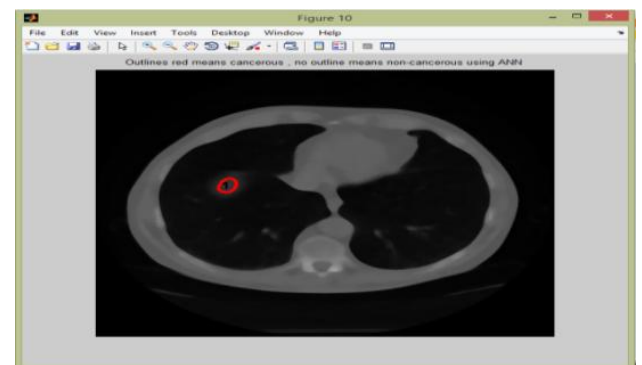

Fig.6. Result after classification lung region with red outline(cancerous)

\begin{tabular}{|c|c|c|c|}
\hline I Feature & _Using_GLCM $X$ & & \\
\hline - $1 \times 1$ s stru & elds & & \\
\hline Field 4 & Value & Min & Max \\
\hline$\boxplus$ autoc & {$[1.0048,1.0047]$} & 1.0047 & 1.0048 \\
\hline \# contr & {$[3.2935 \mathrm{e}-04,4.2126 \mathrm{e}-0 \ldots$} & $3.2935 \ldots$ & $4.2126 \ldots$ \\
\hline \$ corrm & {$[0.9001,0.8722]$} & 0.8722 & 0.9001 \\
\hline \# corrp & {$[0.9001,0.8722]$} & 0.8722 & 0.9001 \\
\hline \# cprom & {$[0.0239,0.0233]$} & 0.0233 & 0.0239 \\
\hline \#cshad & {$[0.0122,0.0119]$} & 0.0119 & 0.0122 \\
\hline \# dissi & {$[3.2935 \mathrm{e}-04,4.2126 \mathrm{e}-0 . \ldots$} & $3.2935 \ldots$ & $4.2126 \ldots$ \\
\hline \# energ & {$[0.9964,0.9963]$} & 0.9963 & 0.9964 \\
\hline \# entro & {$[0.0144,0.0148]$} & 0.0144 & 0.0148 \\
\hline$\boxplus$ homom & {$[0.9998,0.9998]$} & 0.9998 & 0.9998 \\
\hline$\boxplus$ homop & {$[0.9998,0.9998]$} & 0.9998 & 0.9998 \\
\hline maxpr & {$[0.9982,0,9981]$} & 0.9981 & 0.9982 \\
\hline Mosvh & {$[0.5666,0.5666]$} & 0.5666 & 0.5666 \\
\hline 五 savgh & {$[2.0033,2.0033]$} & 2.0033 & 2.0033 \\
\hline \#varh & {$[3.9631,3.9613]$} & 3.9613 & 3.9631 \\
\hline \#senth & {$[0.0141,0.0146]$} & 0.0141 & 0.0146 \\
\hline \# dvarh & {$[3.2935 \mathrm{e}-04,4.2126 \mathrm{e}-0 . \ldots$} & $3.2935 \ldots$ & $4.2126 \ldots$ \\
\hline 画 denth & {$[0.0030,0.0037]$} & 0.0030 & 0.0037 \\
\hline inf1h & {$[-0.8254,-0.7854]$} & -0.8254 & -0.7854 \\
\hline 田 inf2h & {$[0.1413,0.1379]$} & 0.1379 & 0.1413 \\
\hline 五indnc & {$[0.9999,0.9999]$} & 0.9999 & 0.9999 \\
\hline \#idmnc & {$[0.9999,0.9999]$} & 0.9999 & 0.9999 \\
\hline
\end{tabular}

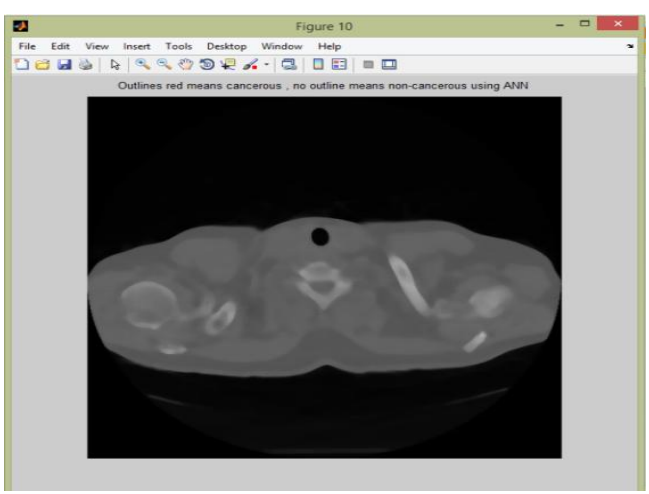

Fig.7. Result after classification lung region without red outline(not

\begin{tabular}{|c|c|c|c|c|}
\hline$\underline{\underline{E}}$ & \multicolumn{4}{|c|}{ Feature_Extraction_Using_GLCM $\times$} \\
\hline \multicolumn{5}{|c|}{-E $1 \times 1$ struct with 22 fields } \\
\hline \multicolumn{2}{|c|}{ Field -} & Value & Min & Max \\
\hline 田 & autoc & {$[1,1]$} & 1 & 1 \\
\hline 画 & contr & {$[0,0]$} & 0 & 0 \\
\hline 宙 & corrm & {$[\mathrm{NaN}, \mathrm{NaN}]$} & $\mathrm{NaN}$ & $\mathrm{NaN}$ \\
\hline 崮 & corrp & {$[\mathrm{NaN}, \mathrm{NaN}]$} & $\mathrm{NaN}$ & $\mathrm{NaN}$ \\
\hline 田 & cprom & {$[0,0]$} & 0 & 0 \\
\hline 更 & cshad & {$[0,0]$} & 0 & 0 \\
\hline 苗 & dissi & {$[0,0]$} & 0 & 0 \\
\hline 田 & energ & {$[1,1]$} & 1 & 1 \\
\hline I & entro & {$[-2.2204 \mathrm{e}-16,-2.2204 \mathrm{e} \ldots$} & $-2.220 \ldots$ & $-2.220 \ldots$ \\
\hline 苗 & homom & {$[1,1]$} & 1 & 1 \\
\hline 崮 & homop & {$[1,1]$} & 1 & 1 \\
\hline 藍 & $\operatorname{maxpr}$ & {$[1,1]$} & 1 & 1 \\
\hline 画 & sosvh & {$[0.5625,0.5625]$} & 0.5625 & 0.5625 \\
\hline 苗 & savgh & {$[2,2]$} & 2 & 2 \\
\hline 宙 & svarh & {$[4,4]$} & 4 & 4 \\
\hline 田 & senth & {$[-2.2204 \mathrm{e}-16,-2.2204 \mathrm{e} \ldots$} & $-2.220 \ldots$ & $-2.220 \ldots$ \\
\hline & dvarh & {$[0,0]$} & 0 & 0 \\
\hline 苗 & denth & {$[-2.2204 \mathrm{e}-16,-2.2204 \mathrm{e} \ldots$} & $-2.220 \ldots$ & $-2.220 \ldots$ \\
\hline 宙 & $\inf 1 \mathrm{~h}$ & {$[0,0]$} & 0 & 0 \\
\hline 畐 & inf $2 \mathrm{~h}$ & {$[0,0]$} & 0 & 0 \\
\hline 画 & indnc & {$[1,1]$} & 1 & 1 \\
\hline 丒 & idmnc & {$[1,1]$} & 1 & 1 \\
\hline
\end{tabular}
cancerous)

Fig 8: Image 1 with Features Values

Fig 9: Image 2 with Features Values 


\section{Computer System for Perception of Lung Cancer}

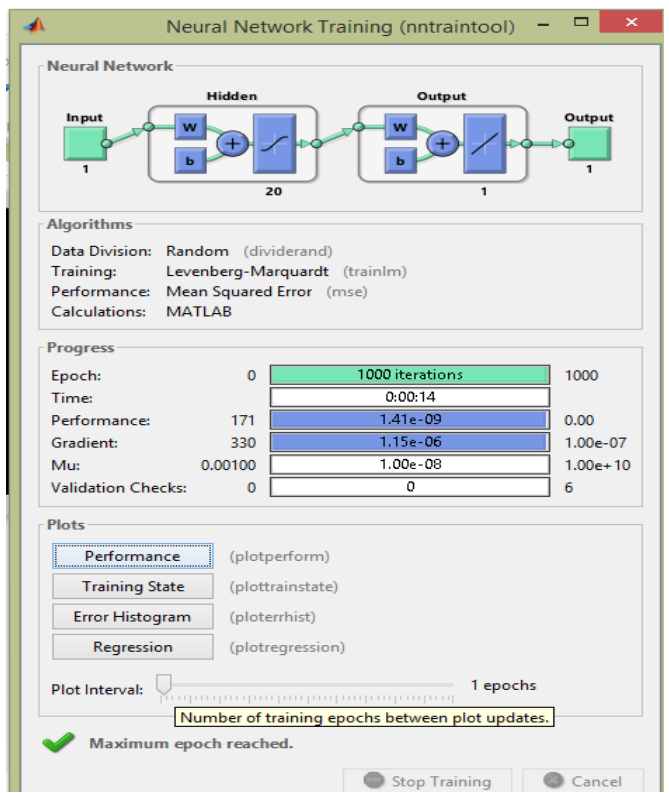

Fig 10: classification using BPNN training (Image1)

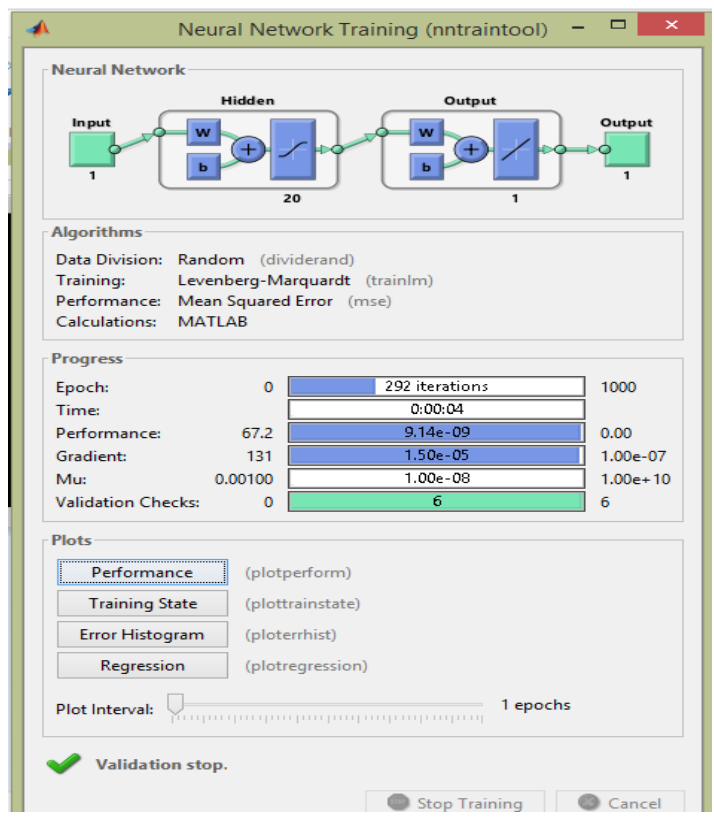

Fig 11: classification using BPNN training (Image2)

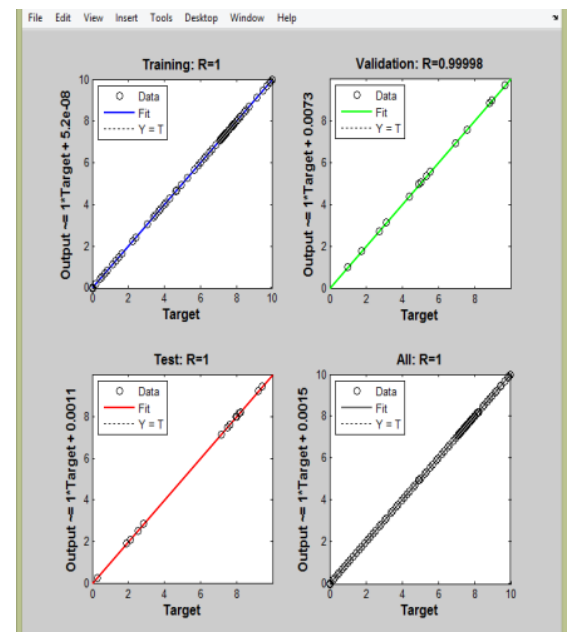

Fig12: Image 1 with Training and Testing Back Propagation

Neural Network

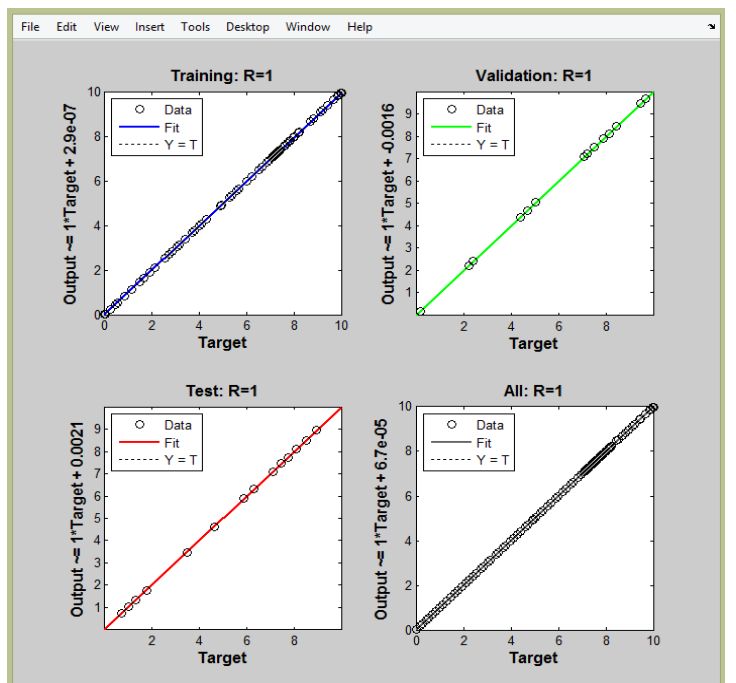

Fig13: Image 2 with Training and Testing Back Propagation Neural Network

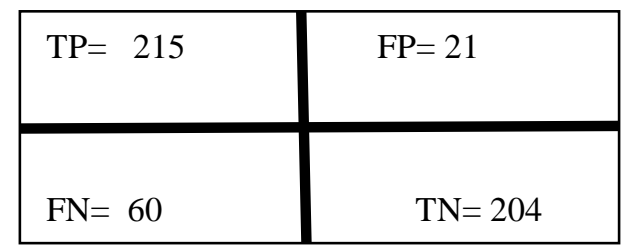

Fig 14: Binary classification confusion matrix for BPNN training

\section{CONCLUSION AND FUTURE WORK}

In analysis of 70 patients which contains 500 image experiment is performed. The neural network classifier gives accurate diagnosis for classify the images. Lung cancer in the early stage is extremely necessary for fast recovery or to reduce the death rate. The dataset can be extended. Results can be compared using different algorithms for classification purpose. The next step will be find the stages in tumor.

\section{REFERENCES}

1. Anita chaudhary, Sonit Sukhraj Singh, "Lung Cancer Detection on CT Images by Using Image Processing", International Conference on Computing Sciences,978-0-7695-4817-3/12, () 2015 IEEE.

2. Shanjuan TAN, Feifei FENG," Study of Aided Diagnosis of Hepatic Carcinoma Based on Artificial Neural Network Combined with Tumor Marker", 2012 International Conference on Medical Physics and Biomedical Engineering, pp.172 - 178, ( 2012 Published by Elsevier

3. Jaspinder Kaur, Nidhi Garg, "An automatic CAD system for early detection of lung tumor using back propagation network", International Conference on Medical Imaging, $\mathrm{m}$-Health and Emerging Communication Systems (MedCom), 978-14799-5097-3/14/, (O2014 IEEE

4. Mellisa Pratiwi, Alexandera, Jeklin Harefa, "Mammograms Classification using Gray-level Co-occurrence Matrix and Radial Basis Function Neural Network", ICCSCI 2015, pp.83 - 91, @ 2015 Published by Elsevier.

5. Bikesh Kumar Singha, Kesari Verma, Adaptive gradient descent backpropagation for classification of breast tumors in ultrasound imaging, International Conference on Information and Communication Technologies(ICICT), pp.1601 - 1609, @ 2015 Published by Elsevier.
Published By:

Blue Eyes Intelligence Engineering \& Sciences Publication 
6. Masaood A. Hussain, Tabassum M. Ansari, "Lung Cancer Detection Using Artificial Neural Network \& Fuzzy Clustering”, International Journal of Advanced Research in Computer and Communication Engineering, Vol. 4, Issue 3, March 2015

7. Shiying Hu, Eric A Huffman, and Jospe h M. Reinhardt," Automatic lung segmentation for accurate quantitiation of volumetric X-Ray CT images", IEEE Transactions on Medical Imaging, vol. 20, no. 6 ,pp. 490 -498, June 2001.[20] R. M. Haralick, K. Shanmugam, and I. Dinstein, "Textural Features for Image Classification," IEEE Transactions on Systems, Man, and Cybernetics, vol. 3, no. 6, pp. 610-621, Nov. 2010 .

8. NehaTripathi and S. P. Panda, "A Review on Textural Features Based Computer Aided Diagnostic System for Mammogram Mass Classification Using GLCM \& RBFNN," International Journal of Engineering Trends and Technology (IJETT), vol. 17, no. 9, pp. 462-464, Nov. 2014.

9. Nguyen, H. T., et al "Watersnakes: Energy-Driven Watershed Segmentation", IEEE Transactions on Pattern Analysis and Machine Intelligence, Volume 25, Number 3, pp.330-342, March 2003

10. American Society of Clinical Oncology. Progress \& Timeline. Accessed

www.cancerprogress.net/timeline/major-milestones-against-cancer on June 12, 2014.

11. Gallant, S. I., "Perceptron-based learning algorithms." IEEE transaction on Neural Networks, vol. 1, no. 2. Pp. 179-1911, 1990.

12. W. McCulloch, W.Pitts, "A logical calculus of the Ideas immanent in nervous activity," Bulletin of Mathematical Biophysics, Vol. 5, pp. $115-133,1943$

13. Detterbeck FC, Decker RH, Tanoue L, Lilenbaum RC. Chapter 41: Non-small cell lung cancer. In: DeVita VT, Lawrence TS, Rosenberg SA, eds. DeVita, Hellman, and Rosenberg's Cancer: Principles and Practice of Oncology. 10th ed. Philadelphia, Pa: Lippincott Williams \& Wilkins; 2015.

14. National Cancer Institute. Physician Data Query (PDQ). Non-Small Cell Lung Cancer Treatment. 2015. Accessed at www.cancer.gov/types/lung/hp/non-small-cell-lungtreatment- pdq on November 25, 2015.

15. American Lung Association. Lung Cancer Screening: Coverage in Health Insurance Plans. Accessed at www.lung.org/assets/documents/lung-cancer/interactive library/lungcancer-screening- implementation. Pdf on February 18 2016.

16. National Comprehensive Cancer Network. NCCN Clinical Practice Guidelines in Oncology: Lung Cancer Screening. V.1.2016. Accessed at www.nccn.org/professionals/physician_gls/pdf/lung_screening.pdf on February 18, 2016

\section{AUTHORS PROFILE}

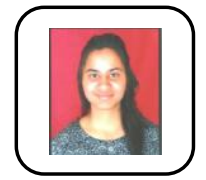

Rakhi Nautiyal, Assistant professor DIT University Dehradun. Research areas are Image Processing, Machine Learning.

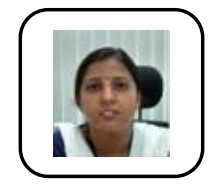

Priyanka Dahiya, working as Assistant Professor in DIT University, Dehardun. She is currently pursuing the Ph.D. degree with Manipal University Jaipur, Rajasthan, India. She is currently working in DIT University, Dehardun. Her current research interests include data mining, Operating System, Deep Learning and Big data. 